\title{
Application of Differential Scanning Calorimetry to Measure the Differential Binding of Ions, Water and Protons in the Unfolding of DNA Molecules
}

Chris M. Olsen, Ronald Shikiya, Rajkumar Ganugula, Calliste Reiling-Steffensmeier, Irine Khutsishvili, Sarah E. Johnson, and Luis A. Marky

Department of Pharmaceutical Sciences, University of Nebraska Medical Center, 986025

Nebraska Medical Center, Omaha, Nebraska 68198-6025 
Abstract The overall stability of DNA molecules globally depends on base-pair stacking, base-pairing, polyelectrolyte effect and hydration contributions. In order to improve our understanding of the role of ions, water and protons in the stability and melting behavior of DNA structures, we report an experimental approach to determine the differential binding of ions $\left(\Delta n_{\text {ion }}\right)$, water $\left(\Delta n_{\mathrm{W}}\right)$ and protons $\left(\Delta n_{\mathrm{H}}{ }^{+}\right)$in the helix-coil transition of DNA molecules. A combination of differential scanning calorimetry (DSC) and temperature-dependent UV spectroscopic techniques were used to investigate the unfolding of a variety of DNA molecules: salmon testes DNA (ST-DNA), one dodecamer, one undecamer and one decamer duplexes, nine hairpin loops as a function of the GC content of their stem, and two triplexes. We determined complete thermodynamic profiles, including all three linking numbers, for the unfolding of each molecule. The favorable folding of a DNA helix results from the typical compensation of favorable enthalpy, unfavorable entropy contributions, and negligible heat capacity effects. DSC thermograms and UV melts as a function of salt, osmolyte and proton concentrations yielded releases of ions, water and protons (for the triplex with $\mathrm{C}^{+} \mathrm{GC}$ base triplets). Therefore, the favorable folding of each DNA molecule results from the formation of base-pair stacks and uptake of both counterions and water molecules. Furthermore, the folding of a DNA duplex is accompanied by a lower uptake of ions and a similar uptake of four water molecules as the DNA helix gets shorter. In addition, the oligomer duplexes and hairpin thermodynamic data suggest ion and water binding depends on the DNA sequence rather than DNA composition. 


\section{INTRODUCTION}

The particular structure of a nucleic acid is controlled by its base sequence in a precise and potentially predictable way. However, knowledge of the structure of a particular duplex alone cannot provide an understanding of the forces responsible for maintaining the distinct structures of nucleic acids. To understand how nucleic acids carry out their biological roles, it is essential to have a complete physical description of how their folding takes place. The overall physical properties of a nucleic acid molecule not only depends on its chemical architecture, but on contributions from base-pairing, base stacking, and ion and water binding (1).

One of the most important physical properties of DNA is its polyelectrolyte behavior, for instance, the repulsive forces between its charges play a role in its conformation (2). Charge repulsion favors extended conformations and as a result DNA is considered a stiff molecule with a persistence length of $\sim 160$ base-pairs that changes if its charge distribution is altered (2). Experimental evidence has shown that phosphate neutralization can induce DNA bending $(3,4)$ and theoretical investigations have suggested that an unbalanced electrostatic repulsion between the remaining phosphate charges could lead to a spontaneous collapse of DNA (5).

Water also plays a fundamental role in the stability and overall secondary and tertiary structure of nucleic acids and proteins $(6,7)$. Experimental and theoretical investigations have indicated that nucleic acid double helices are heavily hydrated $(6,8-12)$. In solution, the overall hydration of a nucleic acid duplex depends on its conformation, nucleotide composition and sequence (13-20). However, in spite of extensive investigations on the hydration of nucleic acids, the detailed nature of this phenomenon remains unknown. 
The main reason for this is the simultaneous presence of two distinctive types of hydrating water around a nucleic acid molecule: hydrophobic or structural (around nonpolar groups) and electrostricted (around polar and/or charged groups) $(21,22)$. These two types of water are difficult to detect and differentiate, complicating the measurement and analysis of their physical properties. Furthermore, the overall hydration of a nucleic acid molecule is closely associated with its number and type of condensed cations because these counterions are also hydrated $(23,24)$.

The crystal structures of acetyl cytosine (25), poly (dC) and poly (rC) $(26,27)$ has confirmed that poly $\mathrm{dC}$ form parallel duplexes stabilized by $\mathrm{C}_{\bullet} \mathrm{C}^{+}$base-pairs at acidic $\mathrm{pH}$. The results showed that cytosine rich sequences could adopt complex $\mathrm{pH}$-dependent conformations. One example is from the crystal structure of d-TCCCCC $(28,29)$, in which two parallel stranded $\mathrm{C}_{\bullet} \mathrm{C}^{+}$duplexes with an antiparallel orientation form a four stranded structure called the i-motif. The base-pairs of one $\mathrm{C}_{\bullet} \mathrm{C}^{+}$duplex intercalate into those of the other duplex, hence, the structure is called the i-motif or the intercalated motif. The base planes of the stacked $\mathrm{C} \mathrm{C}^{+}$base-pairs are perpendicular to each other with all the bases in the anti-conformation. Another example is the stabilizing effect of acidic $\mathrm{pH}$ on the $\mathrm{C} \bullet \mathrm{G}^{*} \mathrm{C}^{+}$base-triplets that are present in homopyrimidine triplexes (30).

In the folding/unfolding of a nucleic acid duplex, it is important to take into account contributions from the conformation and physical and chemical properties of all participating species. These contributions include: i) base stacking interactions, hydration and ion binding from the single and complementary strands; and ii) basepairing and base-pair stacking of the particular duplex conformation, as well as its overall hydration and counterion binding. These non-covalent interactions depend on the actual 
chemical composition of the strands used. In general, the formation of a particular duplex is accompanied by a favorable free energy term, an enthalpy-entropy compensation, uptake of ions and immobilization of water molecules.

In order to improve our understanding of the role of ions, water and protons in the stability and melting behavior of DNA structures, we derived the relevant equations and describe how these equations can be used to experimentally determine the differential binding of ions $\left(\Delta n_{\text {ion }}\right)$, water $\left(\Delta n_{\mathrm{W}}\right)$ and protons $\left(\Delta n_{\mathrm{H}}{ }^{+}\right)$in the helix-coil transition of DNA molecules. Therefore, the main objective of this work is use differential scanning calorimetry (DSC) and complementary UV melting techniques to investigate the temperature induced unfolding of a variety of DNA molecules: ST-DNA, oligonucleotide (ODN) duplexes, short hairpin loops with different GC content of their stem, and two triplexes. Specifically, we determine complete thermodynamic profiles for the unfolding of each molecule and showed how to use these parameters for the measurement of linking numbers: $\Delta n_{\text {ion }}, \Delta n_{\mathrm{W}}$ and $\Delta n_{\mathrm{H}}{ }^{+}$. The overall results showed that in the folding of a DNA duplex a lower uptake of ions and a similar uptake of four water molecules are obtained as the length of the DNA helix decreases.

\section{MATERIALS AND METHODS}

Materials. Salmon Testes DNA (ST-DNA) was obtained from Sigma-Aldrich (product \#D1626), and used without further purification. ODNs were synthesized by the Core Synthetic Facility of the Eppley Institute at UNMC, or by IDT (Coralville IA), purified by reverse phase HPLC purified, and desalted by column chromatography using G-10 Sephadex exclusion chromatography. The sequences of ODNs used in this work and their designation are shown in Table 1. ST-DNA was dissolved overnight in the 
appropriate buffer and dialyzed against this buffer. The concentration of diluted solutions of ST-DNA was determined optically at $260 \mathrm{~nm}$ at room temperature using a molar extinction coefficient, $\varepsilon$, of $12.5 \mathrm{mM}^{-1} \mathrm{~cm}^{-1}$ (in base-pairs), while the solution concentration of ODNs were determined at $260 \mathrm{~nm}$ and $90{ }^{\circ} \mathrm{C}$ with an Aviv Spectrophotometer Model 14DS UV-Vis using the molar extinction coefficients shown in the last column of Table 1 . These values were obtained by extrapolation of the $\varepsilon_{(25)}$ value of the single strand at $25{ }^{\circ} \mathrm{C}$, obtained from the tabulated values for dimers and monomeric bases (31-32), to $90{ }^{\circ} \mathrm{C}$ using procedures reported previously (33-34). This procedure extrapolates the absorbance at $90{ }^{\circ} \mathrm{C}, \mathrm{A}_{90}$, to $25{ }^{\circ} \mathrm{C}, \mathrm{A}_{25}$, using the upper baselines of the ODN UV melting curves and the equation: $\varepsilon_{(90)}=\varepsilon_{(25)}\left(\mathrm{A}_{90} / \mathrm{A}_{25}\right)$. The extinction coefficients of the non-self-complementary duplexes are calculated by averaging the molar extinction coefficients of its component complementary single strands, obtained from their UV melts. Inorganic salts from Sigma were reagent grade, and used without further purification. All measurements were performed in buffer solutions consisting of $10 \mathrm{mM}$ sodium phosphate or $10 \mathrm{mM}$ sodium cacodylate (as indicated) and adjusted to the appropriate experimental conditions of $\mathrm{pH}$, salt concentration, and osmolyte concentration with $\mathrm{HCl}, \mathrm{NaCl}$, and ethylene glycol, respectively. All ODN solutions were prepared by dissolving the dry and desalted ODNs in buffer.

Differential Scanning Calorimetry (DSC). Heat capacity functions of the helix-coil transition of each DNA molecule were measured with a VP-DSC differential scanning calorimeter from Microcal (Northampton, MA). Two cells, the sample cell containing 0.7 $\mathrm{mL}$ of oligomer solution and the reference cell filled with the same volume of buffer 
solution, were heated from $0{ }^{\circ} \mathrm{C}$ to $100{ }^{\circ} \mathrm{C}$ at a heating rate of $0.75{ }^{\circ} \mathrm{C} / \mathrm{min}$. The DSC scans were deconvoluted using a "non-two-state zero $\Delta C p$ model" of the Microcal software and the transition heats were normalized with the strand concentration, according to the molecularity of the complex. The resulting thermograms yielded modelindependent thermodynamic profiles $\left(\Delta H_{\text {cal }}, \Delta S_{\text {cal }}\right.$ and $\left.\Delta G^{\circ}\right)$. These standard thermodynamic profiles and $T_{\mathrm{MS}}$ are obtained from the DSC experiments using the following relationships (34,35): $\Delta H_{\text {cal }}=\int \Delta C_{\mathrm{p}}(T) \mathrm{d} T ; \Delta S_{\text {cal }}=\int \Delta C_{\mathrm{p}}(T) / T \mathrm{~d} T$, and the Gibbs equation, $\Delta G_{(\mathrm{T})}^{\circ}=\Delta H_{\text {cal }}-T \Delta S_{\text {cal }}$; where $\Delta C_{\mathrm{p}}$ is the anomalous heat capacity of the ODN solution during the unfolding process, $\Delta H_{\text {cal }}$ and $\Delta S_{\text {cal }}$ are the unfolding enthalpy and entropy, respectively, assumed to be temperature-independent. $\Delta G^{\circ}$ (T) is the free energy at temperature $T$, normally $20^{\circ} \mathrm{C}$.

Temperature-Dependent UV Spectroscopy. UV melting curves were measured at $260 \mathrm{~nm}$, or $275 \mathrm{~nm}$ for hairpins containing GC base-pairs exclusively, with a thermoelectrically controlled Aviv Spectrophotometer Model 14DS UV-Vis (Lakewood, NJ). The temperature was scanned at a heating rate of $0.6{ }^{\circ} \mathrm{C} / \mathrm{min}$, and shape analysis of the melting curves yielded transition temperatures, $T_{\mathrm{MS}}(35)$. The transition molecularity for the unfolding of a particular complex was obtained by monitoring $T_{\mathrm{M}}$ as a function of the strand concentration. Intramolecular complexes show a $T_{\mathrm{M}}$-independence on strand concentration, while the $T_{\mathrm{M}}$ of intermolecular complexes does depend on strand concentration (34). UV melting curves were carried out as a function of strand concentration (to confirm the molecularity of each complex that forms at low temperatures), salt, osmolyte (ethylene glycol) and $\mathrm{pH}$ to complement the $T_{\mathrm{M}}$ dependences resulting from the DSC unfolding experiments. 


\section{Differential Binding of Counterions, Water and Protons between the helical and}

coil states. The helical and coil states of an ODN are associated with a different number of bound protons, ions and water molecules, therefore, their Helix $\rightarrow$ Coil transition is accompanied by a differential release (or uptake) of protons, counterions and water molecules. The release (or uptake) of each of these species can be measured experimentally using the following starting reaction:

$$
\operatorname{Helix}\left(\mathrm{aNa}^{+}, \mathrm{bH}_{2} \mathrm{O}, \mathrm{cH}^{+}\right) \leftrightarrows \operatorname{Coil}\left(\mathrm{xNa}^{+}, \mathrm{yH}_{2} \mathrm{O}, \mathrm{zH}^{+}\right)+\Delta n_{\mathrm{Na}}+\mathrm{Na}^{+}+\Delta n_{\mathrm{w}} \mathrm{H}_{2} \mathrm{O}+
$$

$\Delta n_{\mathrm{H}}+\mathrm{H}^{+}[1]$

where $\Delta n_{\mathrm{Na}}{ }^{+}=\mathrm{X}-\mathrm{a}, \Delta n_{\mathrm{w}}=\mathrm{y}-\mathrm{b}$ and $\Delta n_{\mathrm{H}}{ }^{+}=\mathrm{z}-\mathrm{c}$. Each of these terms correspond to the differential binding of counterions, water and protons, respectively. These parameters are written on the right hand side of the reaction to indicate a "release", however, if there is an "uptake" of any of these species, they should be written on the left hand side.

The corresponding reaction constant can be written as:

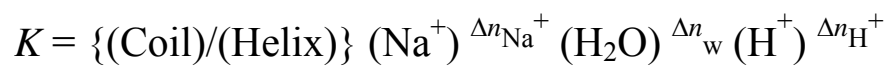

Using a logarithmic function for simplicity:

$$
\ln \mathrm{K}=\ln \mathrm{K}\left\{\mathrm{T}, \mathrm{P}, \ln \left(\mathrm{Na}^{+}\right), \ln \left(\mathrm{H}_{2} \mathrm{O}\right), \ln \left(\mathrm{H}^{+}\right)\right\}
$$

Its total differential at constant "P" and " $\mathrm{T}$ " is equal to:

$\mathrm{d} \ln \mathrm{K}=\left(\partial \ln \mathrm{K} / \partial \ln \left(\mathrm{Na}^{+}\right) \mathrm{d} \ln \left(\mathrm{Na}^{+}\right)+\left(\partial \ln \mathrm{K} / \partial \ln \left(\mathrm{H}_{2} \mathrm{O}\right) \mathrm{d} \ln \left(\mathrm{H}_{2} \mathrm{O}\right)+\left(\partial \ln \mathrm{K} / \partial \ln \left(\mathrm{H}^{+}\right) \mathrm{d} \ln \left(\mathrm{H}^{+}\right)\right.\right.\right.$ each of the three partial differentials corresponds to the desired quantities or linking numbers: $\left.\quad\left\{\partial \ln \mathrm{K} / \partial \ln \left(\mathrm{Na}^{+}\right)\right\}_{\left[\mathrm{H}^{+}\right]\left[\mathrm{H}_{2} \mathrm{O}\right]}=\Delta n_{\mathrm{Na}^{+}}^{+} ; \partial \ln \mathrm{K} / \partial \ln \left(\mathrm{H}_{2} \mathrm{O}\right)\right\}_{\left[\mathrm{H}^{+}\right],\left[\mathrm{Na}^{+}\right]}^{+}=\Delta n_{\mathrm{w}}$

$$
\text { and }\left\{\partial \ln \mathrm{K} / \partial \ln \left(\mathrm{H}^{+}\right)_{\left[\mathrm{H}_{2} \mathrm{O}\right],\left[\mathrm{Na}^{+}\right]}=\Delta n_{\mathrm{H}}{ }^{+}\right.
$$


All three linking numbers are measured experimentally with the assumption that the binding of counterions, water and protons to the helical and coil states of the ODN takes place with a similar type of binding. This is a good assumption for ions and protons, but it may not be correct for water because the helical state of DNA binds primarily electrostricted water, while the random coil state binds primarily structural water. Applying the chain rule to each partial differential and converting ionic activities to concentrations and natural logarithms to decimal logarithms, we obtain:

$$
\begin{aligned}
& \Delta n_{\mathrm{Na}}^{+}=\left(\partial \ln \mathrm{K} / \partial T_{\mathrm{M}}\right)\left(\partial T_{\mathrm{M}} / \partial \ln \left(\mathrm{Na}^{+}\right)=1.11\left[\Delta H_{\mathrm{cal}} / \mathrm{R}_{\mathrm{M}}^{2}\right]\left(\partial T_{\mathrm{M}} / \partial \ln \left[\mathrm{Na}^{+}\right]\right)\right. \\
& \Delta n_{\mathrm{w}}=\left(\partial \operatorname{lnK} / \partial T_{\mathrm{M}}\right)\left(\partial T_{\mathrm{M}} / \ln \mathrm{a}_{\mathrm{w}}\right)=\left[\Delta H_{\mathrm{cal}} / \mathrm{RT}_{\mathrm{M}}^{2}\right]\left(\partial T_{\mathrm{M}} / \partial \ln \mathrm{a}_{\mathrm{w}}\right) \\
& \Delta n_{\mathrm{H}}^{+}=\left(\partial \ln \mathrm{K} / \partial T_{\mathrm{M}}\right)\left(\partial T_{\mathrm{M}} / \partial \ln \left(\mathrm{H}^{+}\right)\right)=-0.434\left[\Delta H_{\mathrm{cal}} / \mathrm{RT}_{\mathrm{M}}{ }^{2}\right]\left(\partial T_{\mathrm{M}} / \partial \mathrm{p} H\right)
\end{aligned}
$$

The first term in each of Eqs $5-7,\left[\Delta H_{\mathrm{cal}} / \mathrm{R} T_{\mathrm{M}}{ }^{2}\right]$, is a constant which is determined directly in differential scanning calorimetric experiments i.e., the enthalpy is model-independent and $\mathrm{R}$ is the gas constant. The second term in parenthesis for each equation is determined from DSC and/or UV melting curves by measuring the dependences of the $T_{\mathrm{M}}$ on the concentration of protons, counterions or water, respectively.

In the determination of $\Delta n_{\mathrm{Na}}{ }^{+}$, DSC and UV melting curves were measured in the range of $16 \mathrm{mM}$ to $200 \mathrm{mM} \mathrm{NaCl}$ at $\mathrm{pH} 7$ and without ethylene glycol. For $\Delta n_{\mathrm{H}}{ }^{+}$, DSC or UV melting experiments were carried out in the $\mathrm{pH}$ range of 5.2 to 7.0 at $16 \mathrm{mM} \mathrm{NaCl}$ and without ethylene glycol. While for $\Delta n_{\mathrm{w}}$, UV-melts as a function of ethylene glycol are carried out at $16 \mathrm{mM} \mathrm{NaCl}$ and at the appropriate $\mathrm{pH}$. The activity of water in these solutions was varied by using different concentrations of ethylene glycol, a co-solute that does not interact specifically with DNA, in the concentration range of 0.6 M-3.0 M (36). 
The osmolality of these solutions were obtained with a UIC vapor pressure osmometer Model 830, which was calibrated with standardized solutions of $\mathrm{NaCl}$. These osmolalities were then converted into water activities $\left(\mathrm{a}_{\mathrm{w}}\right)$ using the following equation (37): $\ln a_{w}=-O s m / M_{w}$; where Osm is the solution osmolality and $M_{w}$ is the molality of pure water (equal to $55.5 \mathrm{~mol} / \mathrm{Kg}$ of $\mathrm{H}_{2} \mathrm{O}$ ). The actual solution conditions used in the determination of linking numbers are noted in the figures and tables presented.

\section{RESULTS and DISCUSSION}

The overall experimental protocol is to use DSC to determine complete thermodynamic profiles for the unfolding of each DNA molecule under a variety of solution conditions. The resulting thermodynamic data allows for the experimental measurement of the two factors involved in the determination of each linking number, $\Delta n_{\mathrm{Na}}{ }^{+}, \Delta n_{\mathrm{W}}$ and $\Delta n_{\mathrm{H}}{ }^{+}$, according to Eqs. 5-7: 1) $\left[\Delta H_{\mathrm{cal}} / \mathrm{R} T_{\mathrm{M}}{ }^{2}\right]$ and 2) the corresponding $T_{\mathrm{M}}$ dependences on salt concentration, $\mathrm{pH}$ and water activity. UV melting curves are done to complement these dependences.

Temperature-Induced Unfolding of ST-DNA. DSC unfolding thermograms of ST$D N A$ at several salt concentrations, ethylene glycol concentration and $\mathrm{p} H$ are shown in Figure 1. The arrows indicate an increase in the concentration of the particular solution condition. We obtained monophasic transitions in all of the solution conditions used: a) the increase in salt concentration (top curve) shifts the helix-coil transition of DNA to higher temperatures, indicating that salt favors the helical state which has the higher charge density parameter (2-4); b) the increase in ethylene glycol concentration or decreasing water activity (middle curve) shifts the helix-coil transition of DNA to lower 
temperatures, indicating that water is favoring the helical state which is more hydrated (6, 8-12); and c) the change in $\mathrm{pH}$ from 5.9 to 7.6 (lower curve) shows negligible shifts of the transition to higher temperatures, this effect is reflecting the acid-base equilibrium of the nucleobases in this $\mathrm{pH}$ range (1).

The top entry of Table 2 shows the thermodynamic profile for the folding of ST-DNA. Its folding at $20{ }^{\circ} \mathrm{C}$ is accompanied by a favorable free energy term resulting from the compensation of favorable enthalpy and unfavorable entropy terms. The $T_{\mathrm{M}}$-dependences on salt concentration, water activity and $\mathrm{pH}$ are shown in Figure 2 A-C, respectively. These $T_{\mathrm{M}}$-dependences were extracted from the DSC and UV melting experiments (data not shown). The differential binding of counterions, $\Delta{n_{\mathrm{Na}}}^{+}$, is determined from Eq. 5. The $\Delta H_{\mathrm{cal}} / \mathrm{R} T_{\mathrm{M}}{ }^{2}$ term and the slope from the $T_{M}$-dependence on salt are $-0.034 \mathrm{~K}^{-1}$ and $8.6{ }^{\circ} \mathrm{C}$, respectively, yielding a $\Delta n_{\mathrm{Na}}{ }^{+}$of $-0.32 \mathrm{~mol} \mathrm{Na} / \mathrm{mol}$ of base-pair, Table 3. Over this range of salt concentration, the negative $\Delta n_{\mathrm{Na}}{ }^{+}$value indicates an uptake of ions. This value is consistent with previous findings for the uptake of ions by DNA polymers ( 38 , 39). The differential binding of water, $\Delta n_{\mathrm{w}}$, is determined from Eq. 6. The $\Delta H_{\text {cal }} / \mathrm{R} T_{\mathrm{M}}^{2}$ term and the slope from the $T_{M}$-dependence on the activity of water are $-0.034 \mathrm{~K}^{-1}$ and $115^{\circ} \mathrm{C}$, respectively, yielding a $\Delta n_{\mathrm{w}}$ value of $-3.7 \mathrm{~mol}$ water $/ \mathrm{mol}$ of base-pair, Table 3 . Over this range of water activities, the negative $\Delta n_{\mathrm{w}}$ value indicates an uptake of water molecules and is consistent with the overall hydration of DNA base-pairs $(10,11,13,14)$. For the determination of the differential binding of protons, $\Delta n_{\mathrm{H}}{ }^{+}$, the $T_{\mathrm{M}}$-dependence on $\mathrm{pH}$ over a range of 5.9 to 7.6 is shown in Figure 2C. The slope of these dependences from DSC and UV melting experiments is similar and equal to $0.91{ }^{\circ} \mathrm{C}$ (Table 3) yielding a $\Delta n_{\mathrm{H}}{ }^{+}$value of $-0.014 \mathrm{~mol}$ protons/mol base-pair, indicating that both helical and coil 
states of DNA have similar proton binding. This is in agreement with the observation that the unfolding of B-DNA can be done with similar results over the $\mathrm{pH}$ range of 6-8, while the stability of DNA outside this ranges varies dramatically (1).

Therefore, in the folding of DNA, the observed exothermic enthalpy corresponds to the net balance of many contributions: base-pairing and base-pair stacking interactions of duplexes, disruption of base stacking interactions of single strands, uptake of water molecules by duplexes and release of structural water from the single strands prior to going into the duplex state. The uptake of counterions is considered to have a negligible heat contribution (40). The unfavorable entropy terms correspond to the contributions of a higher ordered system resulting from the bimolecular association of two strands and the net uptake of water and counterions by the duplex.

\section{Temperature-induced Unfolding of Oligonucleotide Duplexes and Hairpins}

Loops. Typical DSC melts for an ODN self-complementary decamer duplex, $d(G C A T G C A T G C)$, and for a short hairpin $d(G C G C T T T T T G C G C)$ loop are shown in Figures $3 \mathrm{~A}$ and $4 \mathrm{~A}$, respectively. In both cases, the middle curves correspond to thermograms in $10 \mathrm{mM}$ sodium phosphate buffer; additional salt stabilizes the helical state of each DNA molecule resulting in shifting their helix-coil transitions to higher temperatures, while the lowering of the water activity (by the addition of ethylene glycol) destabilizes their helical state shifting the transitions to lower temperatures. We obtained monophasic and broader transitions in all cases, which is characteristic of the unfolding of DNA duplexes with a lower number of base-pairs (41-44). Standard thermodynamic profiles (per mol of duplex or per mol of hairpin) for three ODN duplexes (dodecamer, undecamer and decamer) and for 9 hairpin loops containing 4 or 5 base-pairs in their 
stem are reported in their respective sections of Table 2. The favorable folding of each molecule at $20{ }^{\circ} \mathrm{C}$ results from the characteristic negative enthalpy-entropy compensation. The observed exothermic enthalpies are from base-pair stacking contributions that correspond to the specific stem duplex sequence of each molecule.

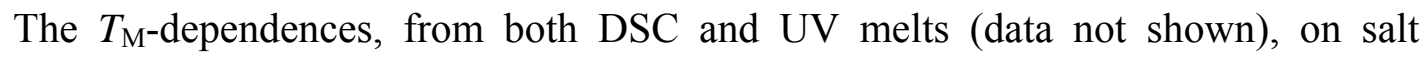
concentration and water activity for the Decamer duplex and GCGC hairpin are shown in Figures $3 \mathrm{~B}$ and $4 \mathrm{~B}$, respectively. The differential binding of counterions, $\Delta n_{\mathrm{Na}}{ }^{+}$, is determined from Eq. 5. The $\Delta H_{\text {cal }} / \mathrm{R} T_{\mathrm{M}}{ }^{2}$ term and the slope from the $T_{M}$-dependence on salt are $-0.28 \mathrm{~K}^{-1}$ and $5.4{ }^{\circ} \mathrm{C}$, respectively, yielding a $\Delta n_{\mathrm{Na}}{ }^{+}$value of $-1.6 \mathrm{~mol} \mathrm{Na}^{+} / \mathrm{mol}$ duplex, Table 3. The GCGC parameters yielded a $\Delta n_{\mathrm{Na}}{ }^{+}$of $-0.37 \mathrm{~mol} \mathrm{Na}{ }^{+} / \mathrm{mol}$ hairpin. In both cases the negative $\Delta n_{\mathrm{Na}}{ }^{+}$values indicate an uptake of ions, much lower than $S T$ $D N A$, but consistent with previous findings for the uptake of ions by shorter ODNs (13, 17, 41-47). The differential binding of water, $\Delta n_{\mathrm{W}}$, is determined from Eq. 6 . We used a $\Delta H_{\text {cal }} / \mathrm{R} T_{\mathrm{M}}{ }^{2}$ term of -0.28 and $-0.15 \mathrm{~K}^{-1}$ for the Decamer and GCGC, respectively, and the slope of the $T_{M}$-dependences on the activity of water are $-105^{\circ} \mathrm{C}$ and $126{ }^{\circ} \mathrm{C}$ yielding $\Delta n_{\mathrm{w}} \mathrm{s}$ of $-29 \mathrm{~mol}$ water/mol duplex and $-19 \mathrm{~mol}$ water/mol hairpin, Table 3. Over this range of water activities, the negative $\Delta n_{\mathrm{W}}$ values indicate an average uptake of 4-5 water molecules per base-pair, similar magnitude ( $\sim$ water molecules) is observed with the $S T$ DNA polymer. The differential binding of protons was not determined for these molecules because these values were considered negligible, see previous section.

\section{Effect of DNA Length and Sequence on the Differential Binding of Ions and}

Water. The $\Delta n_{\mathrm{Na}}{ }^{+}$and $\Delta n_{\mathrm{W}}$ values for three duplexes and 9 hairpin loops are shown in Table 3. These duplexes have at least one helical turn while the hairpins have one-half 
helical turn. In order to analyze the differential binding of counterions as a function of the duplex length, all $\Delta n_{\mathrm{Na}}{ }^{+}$values of Table 3 were normalized per mol of base-pair. In the case of the duplexes, the $\Delta n_{\mathrm{Na}}{ }^{+}$values were divided by the total number (minus one) of base-pairs. The hairpin values, however, were divided by the total number of basepairs in the stem plus one, which corresponds to the two phosphate groups of the loops adjacent to the stem. We obtained values for $\Delta n_{\mathrm{Na}}{ }^{+}$and $\%$ of GC base-pairs of $0.18,60 \%$ (Decamer); 0.27, 63\% (Undecamer); and 0.20, 66\% (Dodecamer), in good agreement with previous findings (41). This gives an overall $\Delta n_{\mathrm{Na}}{ }^{+}$average of $0.22 \mathrm{~mol} \mathrm{Na}^{+}$per mol base-pair. In the case of the hairpins with 4 or 5 base-pairs in the stem, the following values of $\Delta n_{\mathrm{Na}}{ }^{+}$and \% GC base-pairs (in the stem) are obtained: $0.14,40 \% ; 0.13,60 \%$ and $0.10,100 \%$, giving an overall $\Delta n_{\mathrm{Na}}{ }^{+}$average of $0.12 \mathrm{~mol} \mathrm{Na}^{+}$per mol base-pair, as previously obtained for similar stem-loop motifs $(34,42-46)$. In summary, the folding of a DNA duplex yielded $\Delta n_{\mathrm{Na}}{ }^{+}$values (in mol Na${ }^{+} / \mathrm{mol}$ of base pair) of -0.32 (ST-DNA), 0.22 (oligomer duplexes) and -0.12 (hairpins), indicating that ion binding depends on the length of DNA. A lower uptake of ions is obtained, as the DNA helix gets shorter. Furthermore, the results of the oligomer duplexes and hairpins suggest ion binding depends on the DNA sequence rather than DNA composition. The overall effect is consistent with the long-range effects of cations with DNA (1).

The differential binding of water as a function of the duplex length is analyzed in a similar fashion, all $\Delta n_{\mathrm{W}}$ values in Table 3 were normalized per mol of base-pair. Again, in the case of the duplexes, the $\Delta n_{\mathrm{W}}$ values were divided by the total number of base-pairs (minus one) and the hairpin values divided by the total number of base-pairs in the stem (plus one). We obtained values for $\Delta n_{\mathrm{W}}$ and $\%$ of GC base-pairs of $2.9,60 \%$ (Decamer); 
4.4, 63\% (Undecamer); and 5.8, 66\% (Dodecamer), giving an overall $\Delta n_{\mathrm{W}}$ average of 4.3 mol water per mol base-pair. In the case of the hairpins with 4 or 5 base-pairs in the stem, the following values for $\Delta n_{\mathrm{W}}$ and \% GC base-pairs (in the stem) are obtained: 3.5, 40\%; $3.2,60 \%$ and $3.5,100 \%$, giving an overall $\Delta n_{\mathrm{W}}$ average of 3.4 mol water per mol basepair. The overall results indicate that water binding does not depend on the length of DNA; similar uptake of about 4 water molecules is obtained as the DNA helix gets shorter. This is consistent with the short range interaction of water with DNA $(1,8,9)$. However, DNA hydration may well depend on the DNA sequence rather than DNA composition. A larger number of ODNs should be investigated in order to confirm the effect of the DNA sequence, especially if the ion and water linking numbers are expressed in terms of nearest-neighbor effects.

Temperature-Induced Unfolding of a Stable Protonated Triplex. The DSC unfolding of two triplexes was investigated to determine mainly their linking numbers and to examine the effects of cations and protons, along with the interplay within protons and cations, if any. Both triplexes fold intramolecularly and are closed with loops of five cytosines. The stem of the first triplex (AGAGA) contains three TAT and two $\mathrm{C} \mathrm{G}^{*} \mathrm{C}^{+}$ base-triplets, while the second triplex $(7 T A T)$ has seven $\mathrm{T} \bullet \mathrm{A} * \mathrm{~T}$ base triplets. Figure 5A shows the DSC thermograms of AGAGA at pH 6.2 and 5.2 and at two different salts. At low salt, AGAGA yielded monophasic and symmetric transitions at $\mathrm{pH} 5.2$ and 6.2 with similar transition enthalpies, however, the transition at $\mathrm{pH} 5.2$ is more stable, by $\sim 18.2$ ${ }^{\circ} \mathrm{C}$. At high salt concentration (additional $200 \mathrm{mM} \mathrm{NaCl}$ ), both curves are shifted to higher temperatures. These curves show biphasic transitions, a shoulder and a main peak, that correspond to the unfolding of the third strand followed by the unfolding of the 
duplex. A closer inspection of the curves with similar $\mathrm{pH}$ and relative to the low salt curves indicates the shoulders are shifted to lower temperatures, while the main peaks are shifted to higher temperatures. The overall effects are that the increase in salt destabilizes the triplex state and stabilizes the duplex state. The effects are more pronounced at the lower $\mathrm{pH}$, which indicates an interplay between salt and the extent of triplex protonation, consistent with earlier reports (48). Figure 5B shows the DSC thermograms of the 7TAT triplex at several salt concentrations and at a similar $\mathrm{pH}$ of 7 and all transitions are monophasic. The increase in salt concentration shifts all curves to higher temperatures. In this particular case, salt is stabilizing equally the triplex and duplex state of 7TAT.

Table 2 shows standard thermodynamic profiles for the folding of these two triplexes at low salt and $\mathrm{pH}$ 7. The favorable folding of each triplex is enthalpy driven. These exothermic enthalpies correspond to the formation of base-triplet stacks, duplexes and release of hydrophobic water from the single strands prior to going into the duplex state $(30,36,48)$. While, the unfavorable entropy terms correspond to the contributions of a higher ordered system resulting from the intramolecular association of a single strand and the uptake of counterions, water molecules and protons $(1,13,39,48)$.

The $T_{\mathrm{M}}$-dependences, from UV melts, on salt concentration at $\mathrm{pH} 7 \& 5.2$ for the AGAGA triplex are shown in Figure 6A and the two experimental factors to determine the $\Delta n_{\mathrm{Na}}{ }^{+}$values with Eq. 5 at low salt concentration are shown in Table 3. The folding of this triplex yielded a release of counterions at $\mathrm{pH} 7, \Delta n_{\mathrm{Na}}{ }^{+}=1.0 \mathrm{~mol} \mathrm{Na}{ }^{+} / \mathrm{mol}$ triplex, and a marginal uptake of counterions at $\mathrm{pH} 5.2, \Delta n_{\mathrm{Na}}{ }^{+}=-0.1 \mathrm{~mol} \mathrm{Na}^{+} / \mathrm{mol}$ triplex. A similar uptake of ions was obtained when the salt concentration was increased to $200 \mathrm{mM}$ 
$\mathrm{NaCl}$ at this $\mathrm{pH}$ (data not shown). However, similar experiments for the 7TAT triplex (data not shown) yielded a large uptake of ions at $\mathrm{pH} 7, \Delta n_{\mathrm{Na}^{+}}{ }^{+}=-3.5 \mathrm{~mol} \mathrm{Na}^{+} /$mol triplex (Table 3), corresponding to an ion uptake of $0.16 \mathrm{~mol} \mathrm{Na}+/ \mathrm{mol}$ phosphate (when the 18 phosphates of the triplex stem and 4 phosphates of the adjacent loops are taking into account). The behavior of this triplex towards ion binding is similar to a DNA polymer. The main observation of the different behavior of these two triplexes towards ion binding is explained in terms of the protonation of cytosines that excludes cations.

The $T_{\mathrm{M}}$-dependences on the water activity at $\mathrm{pH} 7$ and at low and high salt for the AGAGA triplex are shown in Figures $6 \mathrm{~B}$, the slope of these lines are similar, $\sim 30{ }^{\circ} \mathrm{C}$, yielding an uptake of water molecules, $\Delta n_{\mathrm{W}}=-12 \mathrm{~mol}$ water $/ \mathrm{mol}$ triplex (Table 3). Under similar conditions, the 7TAT triplex yielded a much higher uptake of water molecules, $\Delta n_{\mathrm{W}}=-56 \mathrm{~mol}$ water/mol triplex (Table 3 ). The overall effect is consistent with the higher hydration observed by ODNs containing exclusively AT base-pairs in their sequence. In addition, this particular triplex forms a hydrophobic groove composed of two chains of thymine methyl groups in the major groove of the duplex component, immobilizing additional water (49).

The $T_{\mathrm{M}}$-dependences on $\mathrm{pH}$ at low and high salt for the AGAGA triplex are shown in Figure 6C and the experimental data to determine the $\Delta n_{\mathrm{H}}{ }^{+}$values using Eq. 7 at low salt concentration and $\mathrm{pH} 7 \& 5.2$ are shown in Table 3. The folding of this triplex yielded a high uptake of protons, $\Delta n_{\mathrm{H}}{ }^{+}$of 2.3 and $2.8 \mathrm{~mol} \mathrm{H}^{+} / \mathrm{mol}$ triplex, respectively. This uptake drops to $-2.6 \mathrm{~mol} \mathrm{H} / \mathrm{mol}$ triplex when the salt concentration is increased by the additional $200 \mathrm{mM} \mathrm{NaCl}$ at $\mathrm{pH} 5.2$ (data not shown). The $\Delta n_{\mathrm{H}}{ }^{+}$for 7 TAT was not measured because it was assumed to be negligible, as seen with the duplexes and hairpin 
molecules. The high uptake of protons by the AGAGA triplex may be explained in terms of two contributions: the full protonation of the two cytosines in the stem and the partial protonation of the cytosines located in the loops of these triplexes $(50,51)$.

\section{CONCLUSIONS}

In this manuscript, we have derived the general equations that can be used to extract thermodynamic linking data from experimental results obtained by a combination of differential scanning calorimetry and optical techniques. We think these experimental protocols will be of widespread interest considering the large increase in efforts designed to characterize thermodynamically the interaction of ions, water molecules and protons to macromolecules that dictate and control the structural preferences of macromolecules in solution. We have used these experimental protocols to obtain the differential binding of ions and water as a function of the DNA length and the associated linking numbers for triple helices of the pyrimidine motif. The results showed ion binding depends on the length of DNA while water binding does not. In the folding of a DNA duplex a lower uptake of ions and a similar uptake of four water molecules are obtained, as the DNA helix gets shorter. Furthermore, the results of the oligomer duplexes and hairpins suggest ion and water binding depends on the DNA sequence rather than DNA composition. However, additional experimental data is needed, using a larger number of ODNs, to determine nearest-neighbor parameters of ion and water binding. Additionally, the present data can be used to predict the thermal stability and overall hydration of a DNA molecule at a given solution condition.

Acknowledgment. This work was supported by Grants MCB-0616005 and MCB1122029 from the National Science Foundation 


\section{REFERENCES}

1. Bloomfield, V.A., Crothers, D.M and Tinoco I. Jr. (2000) Nucleic Acids: Structures, Properties, and Functions, University Science Books, California.

2. Daune, M. (1999) Molecular Biophysics, Trans. W. J. Duffin, Oxford University Press, New York.

3. Strauss, J. K. and L. James Maher, I. (1994) DNA Bending by Asymmetric Phosphate Neutralization. Science, 266, 1829-1834.

4. Maher, J. L., III. (1998) Mechanisms of DNA bending. Curr. Opin. Chem. Biol., 2, 688-694.

5. Manning, G., Ebralidse, K. K., Mirzabekov, A. D. and Rich, A. (1989) An Estimate of the Extent of Folding of Nucleosomal DNA by Laterally Asymmetric Neutralization of Phosphate Groups. J. Biomol. Struct. Dyn., 6, 877-889.

6. Saenger, W. (1984) In Principles of Nucleic Acid Structure; Kantor, G. R., Ed.; Springer-Verlag: New York.

7. Tanford, C. (1968) Protein Denaturation. Adv. Protein Chem., 23, 121-282.

8. Texter, J. (1978) Nucleic acid-water interactions. Prog. Biophys. Mol. Biol., 33, 83-97.

9. Westhof, E. (1988) Water: An integral part of nucleic acid structure. Ann. Rev. Phys. Chem., 17, 125-144.

10. Berman, H. M. (1991) Hydration of DNA. Curr. Opin. Struc. Biol., 1, 423-427.

11. Tunis, M-J. B., Hearst, J. E. (1968) Hydration of DNA. I. Preferential hydration and stability of DNA in concentrated trifluoroacetate solution. Biopolymers., 6 , $1325-1344$. 
12. Garcia, A. E.; Hummer, G. \& Soumpasis, D. M. (1996) In Neutrons in Biology; Schoenborn, B. P.; Knott, R., Eds., Plenum Press: New York, 299-308.

13. Rentzeperis, D., Kupke, D. W., Marky, L. A. (1993) Volume changes correlate with entropies and enthalpies in the formation of nucleic acid homoduplexes: differential hydration of A and B conformations. Biopolymers., 33, 117-125.

14. Mrevlishvili, G. M. (1981) Ratio of natural DNA hydration to the GC content. Dokl. Akad. Nauk SSSR., 260, 761-764.

15. Buckin, V. A.; Kankiya, B. I.; Bulichov, N. V.; Lebedev, A. V.; Gukovsky, V. P.; Sarvazyan, A. P.; Williams, A. R. (1989) Measurement of anomalously high hydration of (dA)n.(dT)n double helices in dilute solution. Nature., 340, 321-322.

16. Macgregor, R. B., Jr.; Chen, M. Y. (1990) Delta V0 of the Na(+)-induced B-Z transition of poly[d(G-C)] is positive. Biopolymers, 29, 1069-1076.

17. Buckin, V. A.; Kankiya, B. I.; Sarvazyan, A. P.; Uedaira, H. (1989) Acoustical investigation of poly(dA).poly(dT), poly[d(A-T)], poly(A).poly(U) and DNA hydration in dilute aqueous solutions. Nucleic Acids Res., 17, 4189-42003.

18. Umehara, T.; Kuwabara, S.; Mashimo, S.; Yagihara, S. (1990) Dielectric study on hydration of B-, A-, and Z-DNA. Biopolymers, 29, 649-656.

19. Preisler, R. S.; Chen, H. H.; Colombo, M. F.; Choe, Y.; Short, B. J., Jr.; Rau, D. C. (1995) The B form to $Z$ form transition of poly(dG-m5dC) is sensitive to neutral solutes through an osmotic stress. Biochemistry, 34, 14400-14407.

20. Rentzeperis, D.; Kupke, D. W.; Marky, L. A. (1994) Differential hydration of dA.dT base pairs in parallel-stranded DNA relative to antiparallel DNA. Biochemistry, 33, 9588-9591. 
21. Frank, H. S.; Evans, M. W. J. Chem. Phys. 1945, 13, 507.

22. Kauzmann, W. (1959) Some factors in the interpretation of protein denaturation. Adv. Protein Chem., 14, 1-63.

23. Millero, F. J. In Water and Aqueous Solutions Horn, R. A., Ed.; WileyInterscience: New York, 1972, pp 519-595.

24. Buckin, V. A.; Kankiya, B. I.; Rentzeperis, D.; Marky, L. A.(1994) $\mathrm{Mg}^{2+}$ recognizes the sequence of DNA through its hydration shell J. Am. Chem. Soc., 116, 9423-9429.

25. Marsh, R.E.; Bierstedt, R.; Eichhorn, E.L. (1962) The crystal structure of cytosine-. 5-acetic acidActa Crystallogr., 15, 310-316.

26. Akinrimisi, E.O.; Sander, C.; and Ts'o, P.O.O. (1963), Properties of helical polycytidylic acid. Biochemistry, 2, 340-344.

27. Inman, R.B. and Baldwin R.L. (1964) Helix-random coil transitions in DNA homopolymer pairs. J.Mol.Biol., 8, 452-469.

28. Gehring, K., Leroy, J.L. and Gueron M. (1993) A tetrameric DNA structure with protonated cytosine.cytosine base pairs. Nature, 363, 561-565.

29. Leroy, J.-L.; Gueron, M.; Mergny, J.-L.; Helene, C. (1994), Intramolecular folding of a fragment of the cytosine-rich strand of telomeric DNA into an i-motif. Nucleic Acids Research, 22, 1600-1606.

30. Soyfer, V.N. and Potaman V.N. (1996) Triple-Helical Nucleic Acids. SpringerVerlag, New York, Inc.

31. Cantor, C. R., Warshaw, M. M. and Shapiro, H. (1970) Oligonucleotide Interactions. III. Circular Dichroism Studies of the Conformation of 
Deoxyoligonucleotides. Biopolymers, 9, 1059-1077.

32. Borer, P.N. (1975). Optical properties of nucleic acids, absorptions and circular dichroism spectra. In: Fasman GD (Eds.) Handbook of Biochemistry and Molecular Biology, 3rd Edition, 589-595.

33. Marky, L. A., Blumenfeld, K. S., Kozlowski, S., and Breslauer, K. J. (1983). Saltdependent conformational transitions in the self-complementary deoxydodecanucleotide d(CGCGAATTCGCG): evidence for hairpin formation. Biopolymers, 22, 1247-1257.

34. Marky, L. A., Maiti, S., Olsen, C. M., Shikiya, R., Johnson, S. E., Kaushik, M., and Khutsishvili, I. (2007). Building blocks of nucleic acid nanostructures: unfolding thermodynamics of intramolecular DNA complexes. In "Biomedical Applications of Nanotechnology" (V. Labhasetwar and D. Leslie-Pelecky, Eds.), pp. 191-225. John Wiley \& Sons, Inc.

35. Marky, L. A., and Breslauer, K. J. (1987). Calculating thermodynamic data for transitions of any molecularity from equilibrium melting curves. Biopolymers, 26, 1601-1620.

36. Spink, C. H. and Chaires, J. B. (1999) Effects of Hydration, Ion Release, and Excluded Volume on the Melting of Triplex and Duplex DNA. Biochemistry, 38, 496-508.

37. Colombo M.F., and Bonilla-Rodriguez, G.O., (1996), The water effect on allosteric regulation of hemoglobin probed in water/glucose and water/glycine solutions. J. Biol. Chem., 271, 4895-4899.

38. Manning, G.S. (1987) The molecular theory of polyelectrolyte solutions with applications to the electrostatic properties of polynucleotides. Quart. Rev. Biophys., 11,179-246.

39. Record, M. T., Jr.; Anderson, C.F.; Lohman, T. M. (1978) Thermodynamic analysis of ion effects on the binding and conformational equilibria of proteins and nucleic acids: The roles of ion association or release, screening, and ion effects on water activity. Quart. Rev. Biophys., 11, 103-178. 
40. Krakauer, H. (1972) A Calorimetric Investigation of the Heats of Binding of Mg ${ }^{++}$to Poly A, to Poly U, and to Their Complexes. Biopolymers, 11, 811-828.

41. Zieba, K., Chu, C.M., Kupke, D.W. and Marky, L.A. (1991) Differential Hydration of dA-dT Base Pairing and dA and dT Bulges in Deoxyligonucleotides. Biochemistry, 30, 8018-8026.

42. Rentzeperis, D. (1994) Thermodynamics and Ligand Interaction of DNA Hairpins (Doctoral Dissertation). New York University.

43. Soto, A.M., Kankia, B.I., Dande, P., Gold, B. and Marky, L.A. (2002) Thermodynamic and Hydration Effects for the Incorporation of a Cationic 3Aminopropyl Chain into DNA. Nucleic Acid Research, 30, 1-10.

44. Shikiya, R., Li, J-S, Gold, B. and Marky L. A., (2005) Incorporation of Cationic Chains in the Dickerson-Drew Dodecamer: Correlation of Energetics, Structure, Ion and Water Binding. Biochemistry, 44, 12582-12588.

45. Record, M.T., Jr., Lohman, T.M. and de Haseth, P.L. (1976) Ion Effects on Ligand-Nucleic Acid Interactions. J. Mol. Biol., 107, 145-158

46. Reiling, C., Khutsishvili, I., Huang, Kai and Marky, L.A. (2015) Loop Contributions to the Folding Thermodynamics of DNA Straight Hairpin Loops and Pseudoknots. J. Phys. Chem. B., 19, 1939-1946.

47. Maiti S., Kankia, B., Khutsishvili, I. and Marky, L.A. (2011) Melting Behavior and Ligand Binding of DNA Intramolecular Secondary Structures. Biophysical Chemistry, 159, 162-171.

48. Soto, A. M., Loo, J. and. Marky, L. A. (2002). Energetic Contributions for the Formation of TAT/TAT, TAT/CGC ${ }^{+}$and $\mathrm{CGC}^{+} / \mathrm{CGC}^{+}$Base Triplet Stacks. J. Am. Chem. Soc., 124, 14355-14363.

49. Soto, A.M., Rentzeperis, D., Shikiya, R., Alonso, M. and Marky, L. A. (2006) Substitution of Deoxythymidine for Deoxyuridine in DNA Intramolecular Triplexes: Unfolding Energetics and Ligand Binding. Biochemistry 45, 30513059.

50. Kaushik, M., Suehl, N. and Marky, L.A. (2007) Calorimetric unfolding of the bimolecular and i-motif complexes of the human telomere complementary strand, d(C(3)TA(2))(4). Biophys Chem., 126, 154-164. 
51. Zimmer, Ch and Venner H. (1966) Protonations in Cytosine in DNA. Biopolymers, 4, 1073-1079. 
Table 1. Sequences, Designations and Extinction Coefficients for Oligonucleotides.

\begin{tabular}{|c|c|c|}
\hline DNA & Designations & $\varepsilon\left(\mathrm{mM}^{-1} \mathrm{~cm}^{-1}\right)$ \\
\hline ST-DNA & & 12.5 \\
\hline \multicolumn{3}{|c|}{ Duplexes } \\
\hline$\overline{\mathrm{d}(\text { GCATGCATGC) }}$ & Decamer & 75.1 \\
\hline $\mathrm{d}(\mathrm{CCATCGCTACC}) / \mathrm{d}($ GGTAGCGATGG) & Undecamer & $98 / 115$ \\
\hline d(CCGGAATTCGCC)/d(GGCGAATTCCGG) & Dodecamer & $112 / 120$ \\
\hline \multicolumn{3}{|c|}{ Hairpins } \\
\hline $\mathrm{d}\left(\mathrm{GCGCT}_{5} \mathrm{GCGC}\right)$ & GCGC & 108 \\
\hline $\mathrm{d}\left(\mathrm{GGCC}_{5} \mathrm{GGCC}\right)$ & GGCC & 113 \\
\hline $\mathrm{d}\left(\mathrm{GTAGCT}_{5} \mathrm{GCTAC}\right)$ & GTAGC & 139 \\
\hline $\mathrm{d}\left(\mathrm{GTTGCT}_{5} \mathrm{GCAAC}\right)$ & GTTGC & 136 \\
\hline $\mathrm{d}\left(\mathrm{GTGACT}_{5} \mathrm{GTCAC}\right)$ & GTGAC & 137 \\
\hline $\mathrm{d}\left(\mathrm{GTGTC}_{5} \mathrm{GACAC}\right)$ & GTGTC & 138 \\
\hline $\mathrm{d}\left(\mathrm{GATACT}_{5} \mathrm{GTATC}\right)$ & GATAC & 145 \\
\hline $\mathrm{d}\left(\mathrm{GTAAC}_{5} \mathrm{GTTAC}\right)$ & GTAAC & 143 \\
\hline $\mathrm{d}\left(\mathrm{GAATC}_{5} \mathrm{GATTC}\right)$ & GAATC & 143 \\
\hline
\end{tabular}

\section{Triplexes}

\begin{tabular}{lll}
\hline d(AGAGAC $_{5}$ TCTCTC $_{5}$ TCTCT $^{\dagger}$ & AGAGA & 210
\end{tabular}

d(AAAAAAA $C_{5}$ TTTTTTTC $_{5}$ TTTTTTT) $^{\dagger} \quad$ 7TAT 273

${ }^{*} S T$-DNA is measured in base-pairs. ${ }^{\dagger} 80^{\circ} \mathrm{C}$ and others are measured by extrapolation of the tabulated values of the dimers and monomer bases from $25^{\circ} \mathrm{C}$ to $90^{\circ} \mathrm{C}$ using the nearest-neighbor model. 
Table 2: Thermodynamic profiles for the Folding of DNA Molecules.

\begin{tabular}{|c|c|c|c|}
\hline $\begin{array}{l}\boldsymbol{T}_{\mathbf{M}} \\
\left({ }^{\circ} \mathbf{C}\right)\end{array}$ & $\begin{array}{c}\Delta G_{(20)}^{0} \\
(\mathrm{kcal} / \mathrm{mol})\end{array}$ & $\begin{array}{c}\Delta H_{\mathrm{cal}} \\
(\mathrm{kcal} / \mathrm{mol})\end{array}$ & $\begin{array}{c}T \Delta S_{\mathrm{cal}} \\
(\mathrm{kcal} / \mathrm{mol})\end{array}$ \\
\hline \multicolumn{4}{|c|}{$S T-D N A^{*}$} \\
\hline 68.9 & $-1.1^{*}$ & $-7.8^{*}$ & $-6.7^{*}$ \\
\hline \multicolumn{4}{|c|}{ Duplexes } \\
\hline \multicolumn{4}{|c|}{ Decamer } \\
\hline 49.3 & -5.3 & -58.6 & -53.3 \\
\hline \multicolumn{4}{|c|}{ Undecamer } \\
\hline 56.9 & -9.4 & -84.2 & -74.8 \\
\hline \multicolumn{4}{|c|}{ Dodecamer } \\
\hline 54.8 & -9.6 & -90.8 & -81.2 \\
\hline \multicolumn{4}{|c|}{ Hairpins } \\
\hline \multicolumn{4}{|c|}{ GCGC } \\
\hline 68.3 & -5.0 & -35.3 & -30.3 \\
\hline \multicolumn{4}{|c|}{ GGCC } \\
\hline 62.7 & -4.0 & -31.7 & -27.7 \\
\hline \multicolumn{4}{|c|}{ GTAGC } \\
\hline 52.5 & -3.9 & -39.4 & -35.5 \\
\hline \multicolumn{4}{|c|}{ GTTGC } \\
\hline 54.8 & -4.4 & -41.8 & -37.4 \\
\hline \multicolumn{4}{|c|}{ GTGAC } \\
\hline 53.3 & -3.5 & -34.1 & -30.6 \\
\hline \multicolumn{4}{|c|}{ GTGTC } \\
\hline 52.3 & -3.6 & -36.7 & -33.1 \\
\hline \multicolumn{4}{|c|}{ GATAC } \\
\hline 40.7 & -2.5 & -37.7 & -35.2 \\
\hline \multicolumn{4}{|c|}{ GTAAC } \\
\hline 43.0 & -2.8 & -38.7 & -35.9 \\
\hline \multicolumn{4}{|c|}{ GAATC } \\
\hline 40.8 & -2.3 & -34.1 & -31.8 \\
\hline \multicolumn{4}{|c|}{ Triplexes } \\
\hline \multicolumn{4}{|c|}{$A G A G A^{*}$} \\
\hline 29.3 & -2.1 & -69.3 & -67.2 \\
\hline 56.7 & -10.4 & -93.9 & -83.5 \\
\hline \multicolumn{4}{|c|}{ 7TAT ${ }^{\dagger}$} \\
\hline 23.2 & -1.0 & -93.9 & -92.9 \\
\hline
\end{tabular}

All values are measured in $10 \mathrm{mM}$ sodium phosphate buffer at $\mathrm{pH} 7$, unless otherwise noted, and reported per mol of oligomer, the exception is ST-DNA that is per base-pair. *The AGAGA triplex was measured in $10 \mathrm{mM}$ sodium cacodylate, $\mathrm{pH} 7.0$ and 5.2, respectively. ${ }^{\dagger}$ The $\mathbf{7 T A T}$ triplex is measured in 10 $\mathrm{mM}$ sodium phosphate, $34 \mathrm{mM} \mathrm{NaCl}$, at $\mathrm{pH} 7$. 
Table 3. Linking Numbers for the Folding of DNA Molecules.

\begin{tabular}{|c|c|c|c|c|c|c|}
\hline$\underset{\mathrm{K}^{-1}}{\Delta H \mathrm{Mcal} / \mathrm{RT}_{\mathrm{M}}{ }^{2}}$ & $\begin{array}{c}\partial T_{\mathrm{M}} / \partial \ln \left[\mathrm{Na}^{+}\right] \\
{ }^{\circ} \mathrm{C}\end{array}$ & $\begin{array}{c}\partial T_{\mathrm{M}} / \partial \ln \left(\mathrm{a}_{\mathrm{w}}\right) \\
{ }^{\circ} \mathrm{C}\end{array}$ & $\begin{array}{c}\partial T_{\mathrm{M}} / \partial \mathrm{pH} \\
{ }^{\circ} \mathrm{C}\end{array}$ & $\begin{array}{c}\Delta n_{\mathrm{Na}}+ \\
(\text { per mol) }\end{array}$ & $\begin{array}{c}\Delta n_{W} \\
\text { (per mol) }\end{array}$ & $\begin{array}{c}\Delta n_{\mathbf{H}^{+}} \\
\text {(per mol) }\end{array}$ \\
\hline \multicolumn{7}{|c|}{$S T-D N A$} \\
\hline-0.034 & 8.6 & 115 & 0.91 & -0.32 & -3.7 & -0.014 \\
\hline \multicolumn{7}{|c|}{ Duplexes } \\
\hline \multicolumn{7}{|c|}{ Decamer } \\
\hline-0.28 & 5.4 & 105 & - & -1.6 & -29 & - \\
\hline \multicolumn{7}{|c|}{ Undecamer } \\
\hline-0.43 & 4.7 & 150 & - & -2.2 & -69 & - \\
\hline \multicolumn{7}{|c|}{ Dodecamer } \\
\hline-0.39 & -6.6 & 127 & - & -2.7 & -48 & \\
\hline \multicolumn{7}{|c|}{ Hairpins } \\
\hline \multicolumn{7}{|c|}{ GCGC } \\
\hline-0.15 & 2.2 & 126 & - & -0.37 & -19 & - \\
\hline \multicolumn{7}{|c|}{ GGCC } \\
\hline-0.14 & 2.8 & 117 & - & -0.42 & -17 & - \\
\hline \multicolumn{7}{|c|}{ GTAGC } \\
\hline-0.19 & 3.3 & 105 & - & -0.68 & -19.6 & - \\
\hline \multicolumn{7}{|c|}{ GTTGC } \\
\hline-0.20 & 3.2 & 111 & - & -0.70 & -22 & - \\
\hline \multicolumn{7}{|c|}{ GTGAC } \\
\hline-0.16 & 3.6 & 110 & - & -0.63 & -18 & - \\
\hline \multicolumn{7}{|c|}{ GTGTC } \\
\hline-0.17 & 3.7 & 132 & - & -0.69 & -23 & - \\
\hline \multicolumn{7}{|c|}{ GATAC } \\
\hline-0.19 & 2.9 & 97 & - & -0.61 & -19 & - \\
\hline \multicolumn{7}{|c|}{ GTAAC } \\
\hline-0.19 & 3.2 & 112 & - & -0.68 & -22 & - \\
\hline \multicolumn{7}{|c|}{ GAATC } \\
\hline-0.17 & 3.3 & 99 & - & -0.64 & -17 & - \\
\hline \multicolumn{7}{|c|}{ Triplexes } \\
\hline \multicolumn{7}{|c|}{$A G A G A^{*}$} \\
\hline-0.38 & -2.3 & 30 & -14.1 & 1.0 & -12 & -2.3 \\
\hline-0.41 & -0.2 & 83 & -15.7 & -0.1 & -34 & -2.8 \\
\hline \multicolumn{7}{|c|}{$7 \mathrm{TAT}^{\dagger}$} \\
\hline-0.54 & -5.9 & 103 & -6.5 & -3.5 & -56 & -1.5 \\
\hline
\end{tabular}

All values are measured in $10 \mathrm{mM}$ sodium phosphate buffer at $\mathrm{pH} 7$, unless otherwise noted, and reported per mol of oligomer, the exception is ST-DNA that is per base-pair. *The AGAGA triplex was measured in $10 \mathrm{mM}$ sodium cacodylate, $\mathrm{pH} 7$ and 5.2, respectively. ${ }^{\dagger}$ The 7 TAT triplex is measured in $10 \mathrm{mM}$ sodium phosphate, $34 \mathrm{mM} \mathrm{NaCl}$, at $\mathrm{pH} 7$. 